\title{
Disseminated intravascular coagulation as a consequence of cerebral damage
}

\author{
F. E. PRESTON, R. G. MALIA, M. J. SWORN, \\ W. R. TIMPERLEY, AND E. K. BLACKBURN \\ From the Departments of Haematology and Neuropathology, United Sheffield Hospitals, \\ and the Department of Pathology, University of Sheffield, Sheffield
}

SYNOPSIS Three cases with intracranial lesions developed evidence of disseminated intravascular coagulation which was confirmed at necropsy. The factors engendering this state, including release of potent thromboplastin from neural tissue are discussed and the danger of this intermediary mechanism of disease increasing the mortality of intracranial disease is demonstrated. Careful haematological investigation of all patients with intracranial disease is therefore advised, especially if they manifest evidence of a bleeding tendency.

It has been suggested that disseminated intravascular coagulation (DIC) is an important intermediary mechanism of disease and death (McKay, 1965). Many clinical entities have been related causally to intravascular coagulation (Nalbandian et al., 1971) and many agents shown to be capable of initiating, promoting, and modifying the effects of DIC (McKay, 1965; Hardaway, 1966; Preston et al., 1972b).

Whatever the initiating agent, the manifestations of DIC are similar in many respects, presenting a spectrum of clinicopathological changes with variable degrees of shock, haemorrhagic diathesis, and parenchymal necrosis, the latter occurring in many different organs (McKay, 1965).

In presenting this series of cases we wish to demonstrate the causal relationship of intracerebral lesions to consumption coagulopathy, to adduce evidence for the ability of such lesions to induce DIC, and to stress the danger of this intermediary mechanism of disease in increasing the morbidity and mortality of intracranial lesions.

\section{CASE 1}

A 38 year old man with a two year history of right chronic otitis media presented with neck stiffness of 10 days' duration. He was drowsy, had nystagmus on looking to the right, ataxia of his upper limbs, dragging of his right leg, marked neck stiffness, and a purulent discharge from his right ear. The haemoglobin ( $\mathrm{Hb})$ level was $17.0 \mathrm{~g} / 100 \mathrm{ml}$. Examination of his cerebrospinal fluid revealed 141 white cells/cu. mm, $90 \%$ of which were lymphocytes. A ventriculogram with iophendylate revealed a space occupying lesion in the right posterior fossa. A right cerebellar abscess was found at operation and the abscess and its capsule were removed. Pus from the ear and abscess

TABLE 1

SUMMARY OF MAIN HAEMATOLOGICAL FINDINGS IN EACH CASE

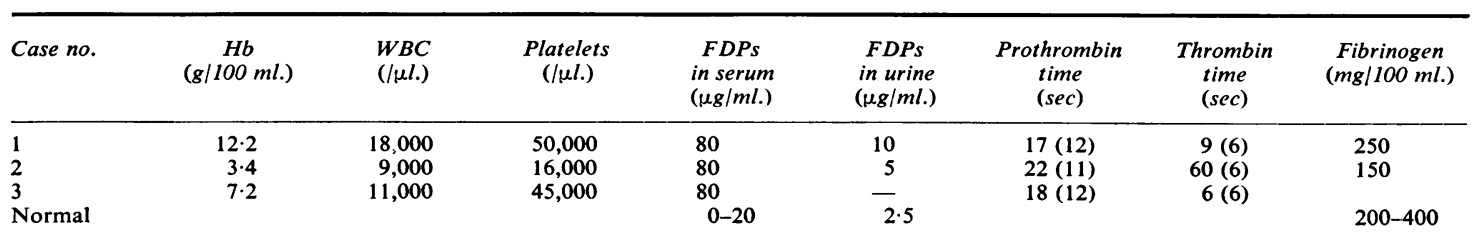




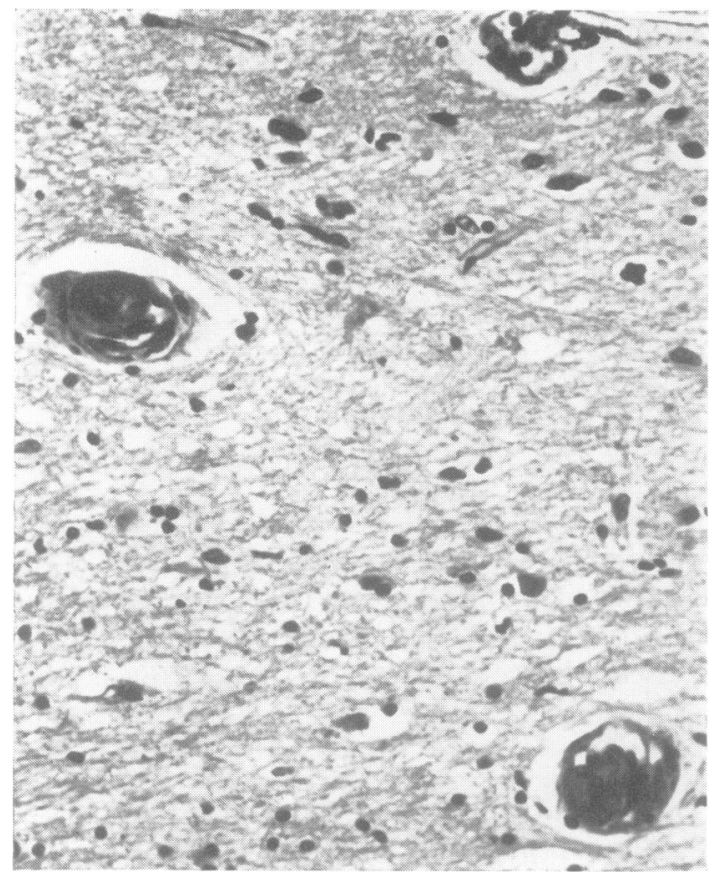

FIG. 1. Case 1. Section of parietal lobe. Occlusion of small vessels by fibrin. $H$ and $E, \times 600$.

revealed heavy growths of Proteus vulgaris and treatment with penicillin, streptomycin, and sulphonamides was instituted. The day after the operation he was alert and moving all four limbs but by the next day he was oliguric with macroscopic haematuria. His blood urea concentration was $310 \mathrm{mg} / 100 \mathrm{ml}$., $\mathrm{Hb} 12.2 \mathrm{~g} / 100 \mathrm{ml}$., and burr cells were noted in a blood film. The results of further haematological investigations are shown in Table 1. Peritoneal dialysis was performed for five days, by which time the blood urea was $150 \mathrm{mg} / 100 \mathrm{ml}$. On the seventh postoperative day his respiratory rate suddenly fell to $6 /$ minute and the blood pressure rose rapidly to $170 / 110 \mathrm{mmHg}$. Ventricular puncture revealed only blood and necrotic tissue, while insertion of a drain and Spitz-Holter valve into the left cerebral ventricle with decompression of the posterior fossa resulted in no improvement in his clinical state. He died the day after this operation.

At post-mortem examination the brain (weight $1,410 \mathrm{~g}$ ) was swollen, more so on the right than the left. Approximately two-thirds of the right cerebellar hemisphere had been removed surgically. A large haemorrhage was present in the centre of the right cerebral hemisphere in the region of the internal capsule and basal ganglia. The haemorrhage had

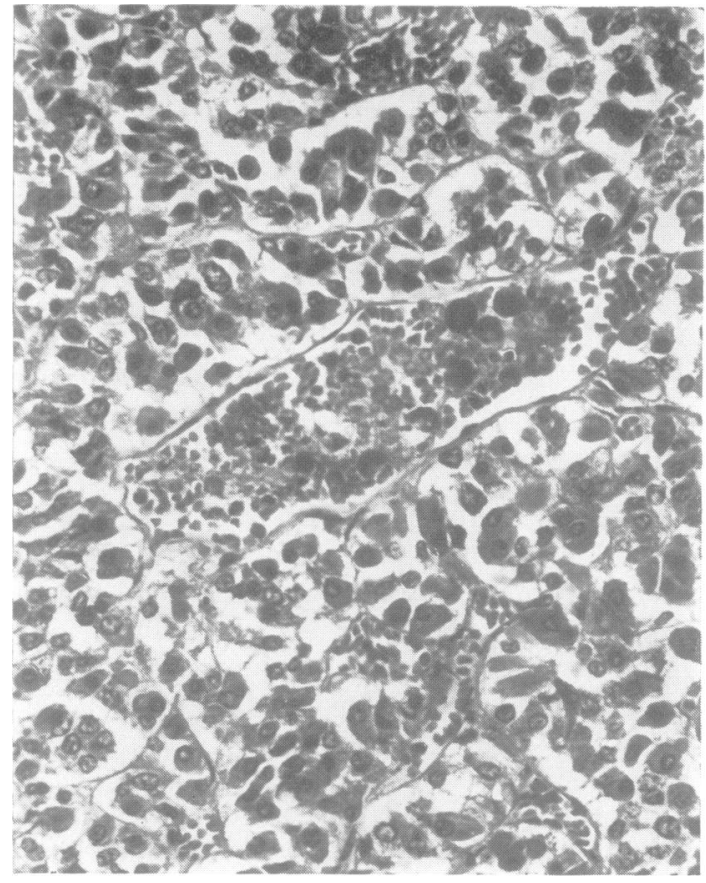

FIG. 2. Case 1. Section of pituitary gland. Clumps of fibrin in small blood-vessels. $H$ and $E, \times 600$.

ruptured into the ventricles, which were full of blood clot. Linear haemorrhages were also present in the mid-brain, presumably as a result of cerebral swelling. The only other macroscopic abnormalities noted were that the heart weighed $425 \mathrm{~g}$ with evidence of marked left ventricular hypertrophy and that the renal calices and pelves and ureters contained a large amount of recent blood clot and brownish debris. Sections of the brain confirmed that the cerebellar abscess had been removed completely.

Histologically, clumps of fibrin were seen in many small vessels of arteriolar or capillary size in the brain (Fig. 1). The pituitary gland showed the presence of aggregates of fibrin within one capillary, but no infarcts were seen (Fig. 2). Many arterioles and capillaries within the kidneys contained plugs of fibrin which appeared to be of various ages (Fig. 3), some showing evidence of organization with ingrowth of fibroblasts; others being more recent with a granular appearance and no evidence of organization. Some glomeruli showed areas of infarction with release of fibrin and cells into the glomerular spaces. An occasional glomerulus was totally infarcted; again the infarcts appeared to be of various ages, some showing evidence of organization. A few small 


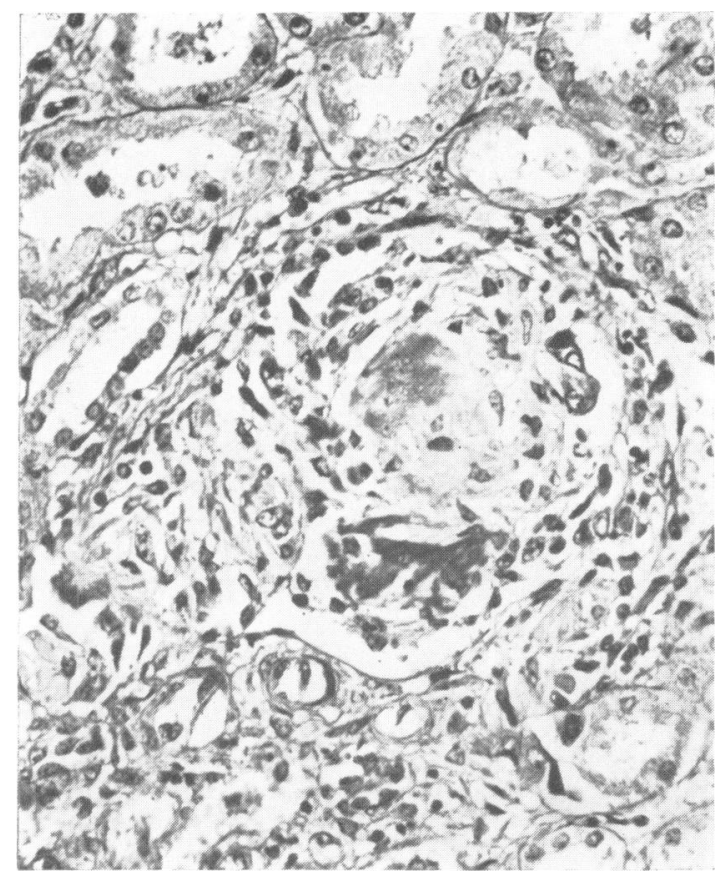

FIG. 3. Case 1. Section of kidney. A glomerulus containing partially organized area of infarction and masses of fibrin. $H$ and $E, \times 600$.

areas of recent haemorrhage and infarction were seen in the renal medulla. There was erythrophagocytosis of red cells by hepatic Kupfer cells; an occasional vessel in the portal tracts contained plugs of fibrin. In the lungs, several small and medium sized vessels contained plugs of fibrin (Fig. 4) and a few small haemorrhages were evident within the alveolar wall spaces. All other organs appeared normal.

\section{CASE 2}

A 9 year old girl was admitted after a road traffic accident. She had frontal scalp haematomas and she responded to painful stimuli only. Both pupils were equal and reacted to light. Four hours later her left pupil was larger than the right and it became unreactive to light. An intracranial echogram showed a $4 \mathrm{~mm}$ shift of the midline structures from left to right and a burr hole revealed a thin subdural clot in the left temporal region and contusion of the lateral aspect of the temporal lobe. She was treated with intravenous mannitol and soon moved all four limbs. Five days later she developed convulsive movements and the left pupil became dilated and unreactive to light. Carotid arteriograms showed a

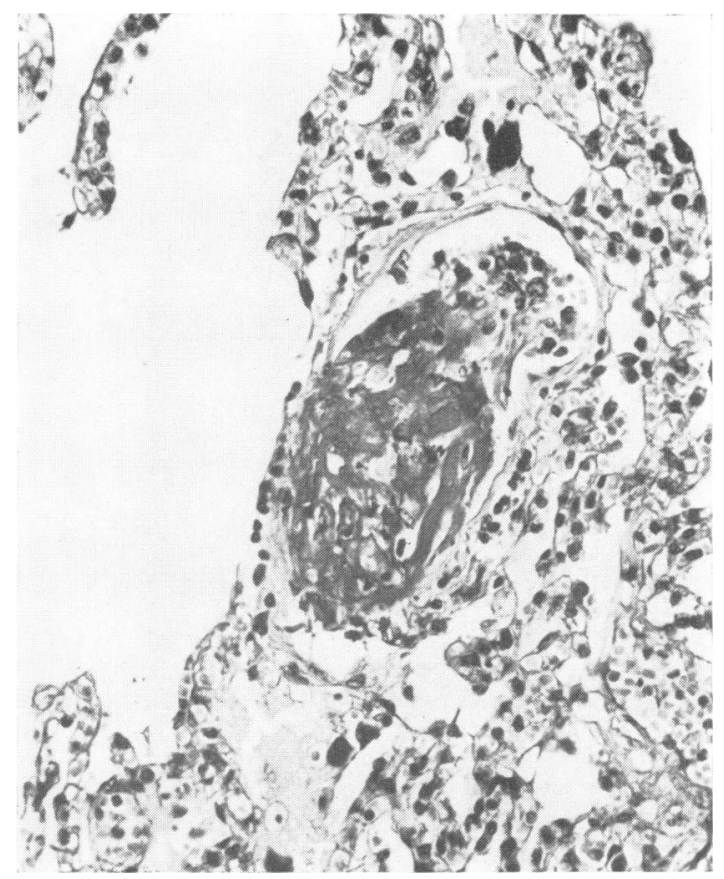

FIG. 4. Case 1. Section of lung. Occlusion of a bloodvessel in an alveolar wall by a mass of fibrin. $H$ and $E$, $\times 600$.

shift of the anterior cerebral artery to the right. A left temporal decompression was performed with slight clinical improvement but the next day she developed profuse gastrointestinal bleeding. Investigations revealed a haemoglobin level of $8.0 \mathrm{~g} /$ $100 \mathrm{ml}$, a platelet count of $68,000 / \mathrm{cu}$. $\mathrm{mm}$, and marked polychromasia of red cells in the blood film. She was treated initially with intravenous infusion of fresh blood and heparin and later with streptokinase but continued to bleed into her gastrointestinal tract. Barium studies failed to reveal any localized gastrointestinal lesion. The next day results were as follows: $\mathrm{Hb} 6 \cdot 1 \mathrm{~g} / 100 \mathrm{ml}$, reticulocytes $4 \%$, platelets $75,000 / \mathrm{cu}$. mm, prothrombin time 17 seconds (control 13 seconds), thrombin time 8 seconds (control 7 seconds), and fibrinogen $150 \mathrm{mg} / 100 \mathrm{ml}$. Her serum and urinary fibrin/fibrinogen degradation products (FDPs) were $80 \mu \mathrm{g} / \mathrm{ml}$. and $2,000 \mu \mathrm{g} / 24$ hours respectively. During the following two days her $\mathrm{Hb}$ level progressively fell to $3.4 \mathrm{~g} / 100 \mathrm{ml}$. and the platelet count to $16,000 / \mathrm{cu}$. $\mathrm{mm}$. The 1-stage prothrombin time was markedly prolonged at 22 seconds, as was the thrombin time at 60 seconds. The relevant investigations are summarized in Table 1 . On the eighth day after admission she developed 


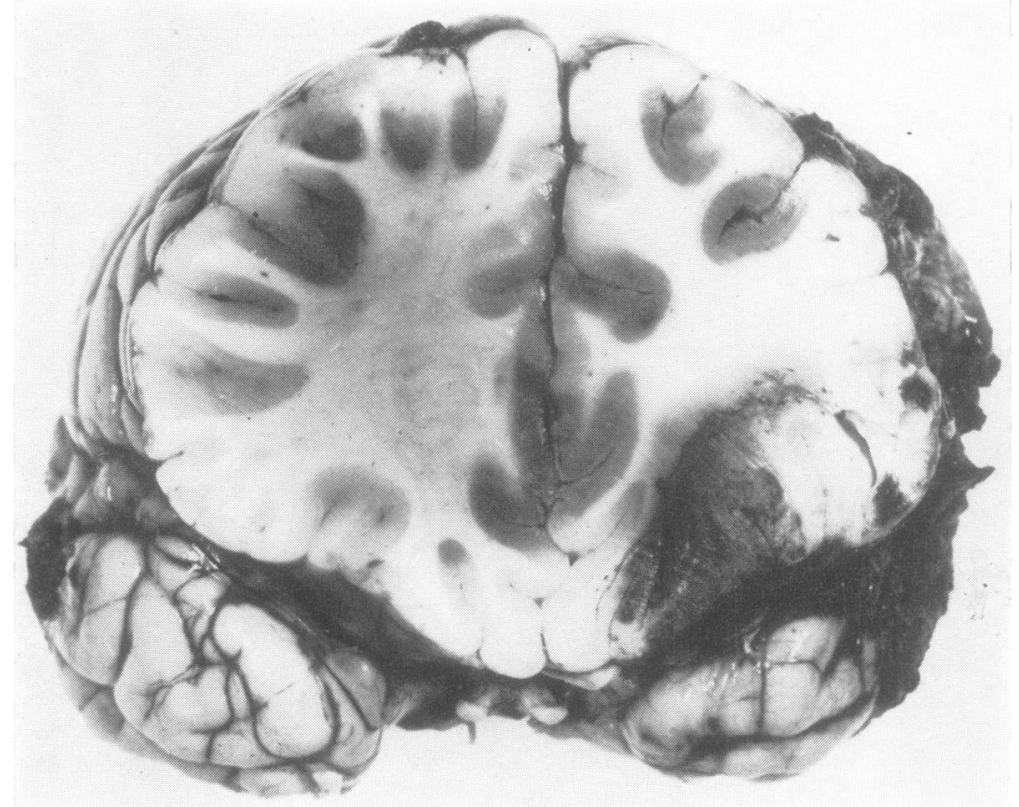

FIG. 5. Case 2. Coronal section through frontal lobe. Area of contusion and areas of early necrosis in cortical grey matter.

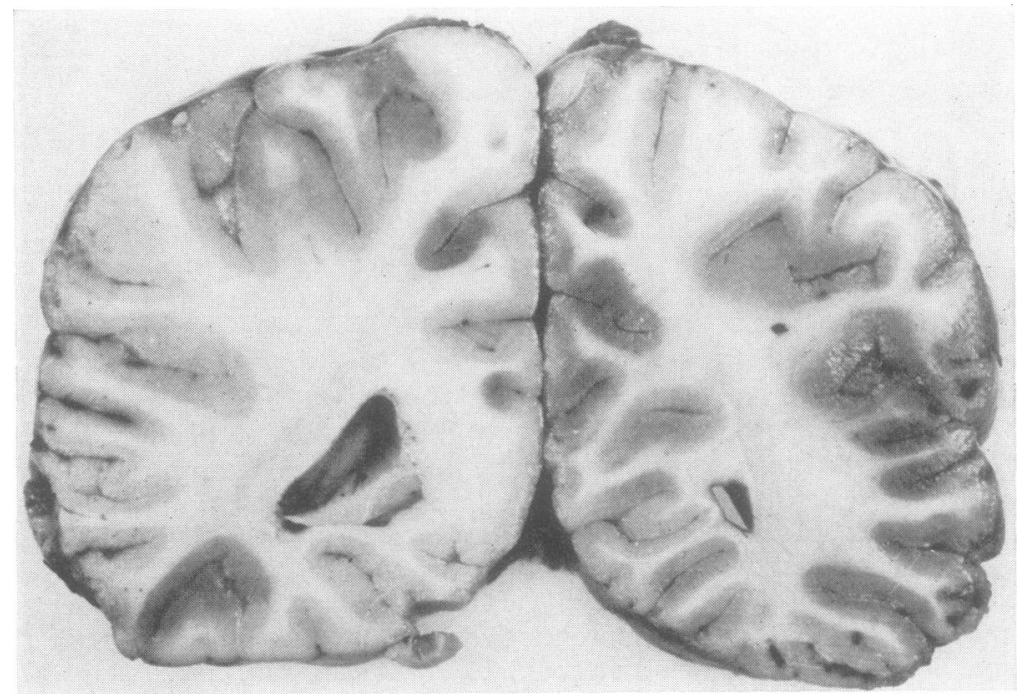

FIG. 6. Case 2. Coronal section through the posterior parietal region of the brain. Numerous areas of early infarction in the cortical grey matter. 


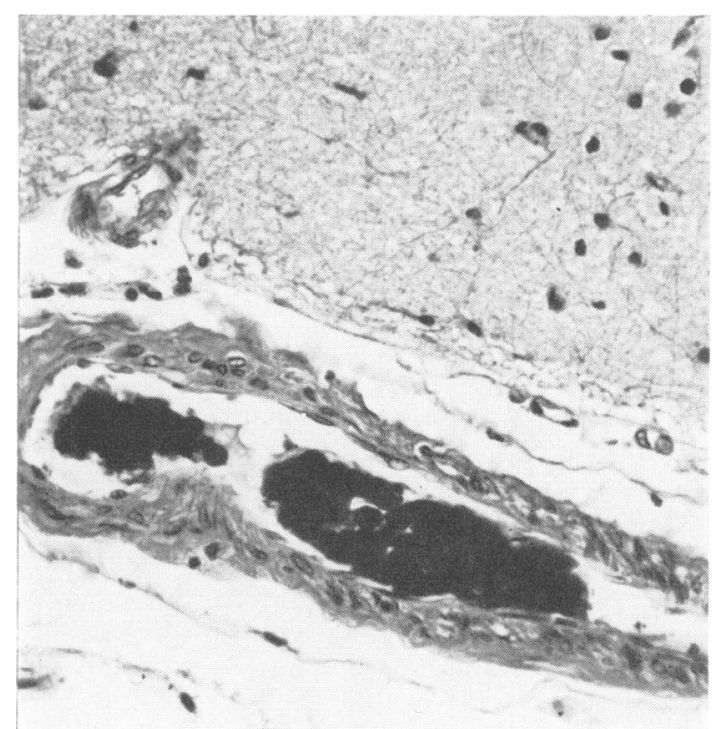

FIG. 7. Case 2. Section of cerebral cortex. Occlusion of a small artery by masses of fibrin. $H$ and $E, \times 600$.

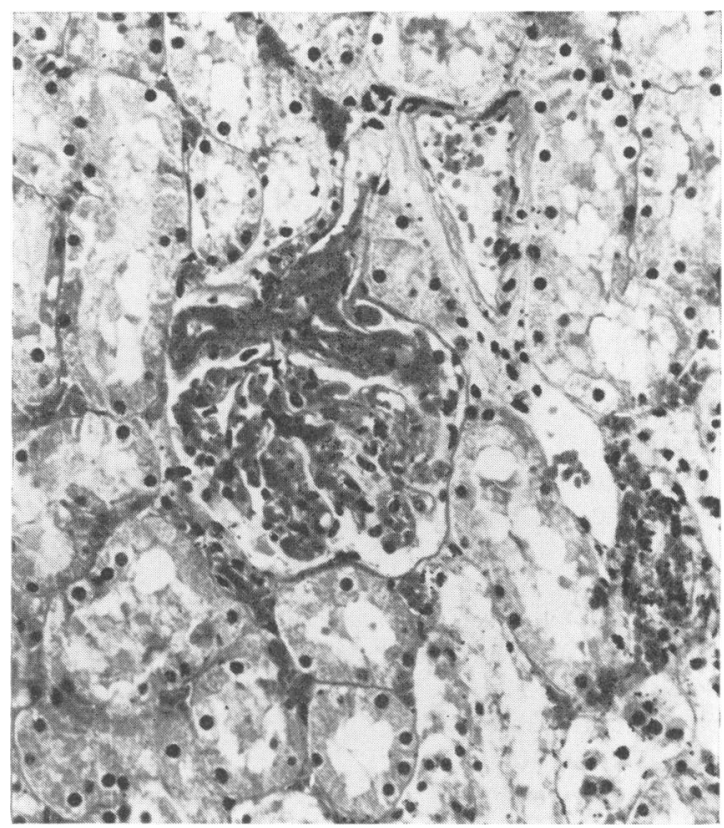

FIG. 8. Case 2. Section of kidney. A glomerulus containing masses of fibrin within the capillaries. $H$ and $E$, $\times 600$.

structures and others were seen in various stages of acute degeneration. There was marked vacuolation of the surrounding neuropil and of the adjacent white matter, with acute swelling of both astrocytes and oligodendrocytes. Many capillaries in the infarcted areas showed evidence of recent haemorrhage. The vessels of several systemic organs also showed evidence of fibrin plugging. The kidneys in particular showed a large amount of this with occlusion of many glomerular arterioles and capillaries (Fig. 8) and affected glomeruli showing areas of partial or complete infarction. Fibrin was present in many tubules. The lungs contained a few recent haemorrhages, both within the pleura and in the alveolar septa and again many small vessels showed evidence of fibrin plugging. Fibrin plugs were also present in the small vessels of the gastrointestinal tract and of the bladder. Petechial haemorrhages were seen in the territory of affected vessels.

\section{CASE 3}

A 26 year old man was admitted after being found unconscious at the bottom of the stairs after drinking heavily. He was restless, showed violent movements of the right arm and both legs, and was incontinent affected areas had lost their nuclei and cytoplasmic 
of urine. The left pupil was larger than the right, but both pupils reacted to light. He was treated conservatively, but in view of deterioration in his respiration three days after admission he was artificially ventilated. Twelve days after admission he showed a tendency to bleed easily from venepuncture sites. Results of investigations were $\mathrm{Hb} 10.5 \mathrm{~g} / 100 \mathrm{ml}$. (compared with $17.9 \mathrm{~g} / 100 \mathrm{ml}$. on admission), platelets $45,000 / \mathrm{cu}$. $\mathrm{mm}, 1$-stage prothrombin time 18 seconds (control 12 seconds), thrombin time 6 seconds (control 6 seconds), and serum FDP's $80 \mu \mathrm{g} / \mathrm{ml}$. On the same day he developed oliguric renal failure, passing only $74 \mathrm{ml}$. of urine with a plasma urea of $480 \mathrm{mg} / 100 \mathrm{ml}$. He was treated by peritoneal dialysis and intravenous heparin-3,000 units four hourly, which was subsequently increased to 5,000 units four hourly. On this therapy his $\mathrm{Hb}$ level fell to $8.0 \mathrm{~g} / 100 \mathrm{ml}$. over the following four days, but his platelet count rose to 90,000 per cu. $\mathrm{mm}$. Microcytes and polychromasia were evident in the blood film during this period. His plasma urea progressively fell to $175 \mathrm{mg} / 100 \mathrm{ml}$. and serum electrolytes were within normal limits. Peritoneal dialysis was therefore discontinued. At this time he developed a staphyloccal chest infection and his peritoneal fluid showed a profuse growth of coliforms and Pseudomonas aeruginosa. He died on the 17th day after admission, the platelet count on this day being $45,000 / \mathrm{cu}$. mm. Results of other haematological investigations are shown in Table 1.

At necropsy there were numerous purpuric haemorrhages on the back, chest, and limbs with pitting oedema of both ankles. The peritoneum contained slightly turbid fluid. There was a large left sided haemorrhagic fibrinous pleural effusion. Section of the partially collapsed lower lobe of the left lung showed the presence of an abscess measuring $3 \mathrm{~cm}$ in diameter. There was evidence of bronchopneumonia in both lungs. Staphylococcus pyogenes was grown from the abscess at postmortem. The stomach, duodenum, small intestine, and large intestine showed the presence of numerous small haemorrhages in the mucosa. There was also evidence of multiple small bleeding points in the retroperitoneal pelvic fat. The bladder mucosa showed a few small petechial haemorrhages. Section of the swollen brain showed an area of necrosis surrounded by recent haemorrhage, in the centre of the corpus callosum. The necrotic area measured $1 \mathrm{~cm}$ in diameter. There was an irregular tear in the upper surface of the corpus callosum just anterior to the necrotic area. An area of contusion $1 \mathrm{~cm}$ in diameter was seen in the grey matter on the inferior aspect of the left frontal lobe just anterior to the temporal pole. The temporal lobes on both sides showed numerous small petechial haemorrhages in the grey and white matter. A few similar areas were also seen in the parietal and occipital lobes. All petechial haemorrhages appeared to be of very recent origin.

Histologically, the area of necrosis and tearing in the corpus callosum showed foamy histiocytes and breakdown of myelin and axons. This damage presumably dated from the original head injury. Petechial haemorrhages in the grey and white matter, however, were clearly more recent in origin and vessels within the territory of the haemorrhages were shown to contain fibrin plugs. Microscopical examination of the midbrain showed several small areas of fibre disruption with the presence of focal accumulation of foamy histiocytes. Some neurones in the area showed evidence of chromatolysis. This also presumably dated from the original injury. The kidneys contained fibrin strands and globules within many tubules and a few plugs of fibrin were szen in glomerular capillaries. An occasional partially infarcted glomerulus was present. Recent petechial haemorrhages in the bladder and intestinal mucosa were confirmed histologically and again an occasional vessel contained a fibrin plug. The retroperitoneap $c$ haemorrhage also appeared to be of recent origine i Both lungs showed evidence of severe haemorrhagio bronchopneumonia and numerous colonies of gran positive cocci were seen. A few vessels containe $\dot{\phi}$ fibrin aggregates.

\section{DISCUSSION}

It has been suggested that throughout life there is continual deposition of fibrin on endothelium which has been damaged by the stresses of the circulation (Fearnley, 1965). After repair the fibrin is removed by the action of the fibrinolytic enzyme system, thus serving to maintain the patency of the vascular tree. There is therefore a delicately balanced equilibrium between the coagulation and fibrinolytic enzyme systems (Nolf, 1908). Increased deposition of fibrin may be a consequence of impaired fibrinolysis or the result of excessive concentrations of coagulant substances within the circulation. Many of the recognized syndromes of disseminated intravascular coagulation (DIC) stem from the rapid release of thromboplastic substances into the circulating blood. The widespread deposition of fibrin is usually associated with a secondary fibrinolytic response resulting in the generation of increased concentrations of fibrin degradation products.

Although Graham and Adams (1971) have described cerebral ischaemic damage in associa- 
TABLE 2

DISTRIBUTION OF FIBRIN IN VARIOUS TISSUES EXAMINED*

\begin{tabular}{lccc}
\hline Organ & Case 1 & Case 2 & Case 3 \\
\hline Brain & 2 & 3 & 2 \\
Heart & 1 & 0 & 0 \\
Kidney & 2 & 3 & 1 \\
Liver & 2 & 0 & 0 \\
Gastrointestinal tract & 0 & 2 & 1 \\
Bladder & 0 & 2 & 1 \\
Pituitary & 1 & 0 & 0 \\
Lung & 2 & 3 & 1 \\
& & & \\
\hline
\end{tabular}

* The degree of involvement is graded 0 to 3 (negative to heavy). No fibrin was seen in the adrenals, thyroid, spleen, or pancreas of any case.

tion with fatal head injuries, there have been surprisingly few reports of DIC complicating brain damage. Cerebral tissue has marked thromboplastic activity; indeed, it is used as a source of tissue thromboplastin in the Quick one-stage prothrombin test. The three patients described in this study developed clinical and haematological features of DIC apparently as a consequence of damage to the brain. A possible additional factor in the first patient was the presence of a cerebral abscess. A variety of abnormalities of the coagulation mechanism have been described as a consequence of bacterial infection and it has been suggested that they may be a reflection of intravascular coagulation (Goldenfarb et al., 1970; Preston et al., in press).

The diagnosis of DIC was made on the basis of thrombocytopenia, prolongation of thrombin and prothrombin times, and elevation of serum fibrin degradation products (FDP). A bleeding diathesis, as evidenced by generalized bruising and excessive bleeding from venepuncture sites was observed in each patient. The abnormal bleeding state which accompanies DIC results from the consumption of clotting factors and platelets together with the anticoagulant properties of the FDP's (Marder and Shulman, 1969; Larrieu et al., 1972).

It is of considerable interest that renal failure occurred in all three patients and that intraglomerular fibrin was demonstrated in each case by histological examination of necropsy material. There has been much recent discussion on the role of intraglomerular fibrin in the pathogenesis of various renal disorders and Clarkson et al. (1970) have expressed the view that intraglomerular coagulation plays an important role in the production of acute renal failure. The increased concentrations of urinary FDPs in two of the three patients were considered to reflect lysis of intraglomerular fibrin.

The haematological diagnosis of DIC was subsequently confirmed by histological examination of necropsy material. Cerebral and renal vessels were involved in all three patients, gastrointestinal and bladder vessels in two, and hepatic involvement was noted in one patient (Table 2). The organ distribution of fibrin which occurs in DIC is incompletely understood but Regoeczi and Brain (1969) have demonstrated that an important factor, at least in the experimental animal, is the rate of fibrin formation and that this dictates the actual dimensions of the insoluble fibrin strands.

A disturbing feature of two of the cases described here is the relatively trivial head injury which precipitated the profound disturbances of the coagulation fibrinolytic mechanism. The outcome, in this group of patients, illustrates the grave prognosis when this syndrome occurs as a consequence of cerebral damage. Clearly, early diagnosis is vital and we believe that early heparin therapy may be of value in the management of this type of patient. There is also a need for a carefully controlled investigation of this syndrome in a larger series of cases with damage to the nervous system, as it seems likely that it is far more common than is at present realized. It may also be that intravascular coagulation plays a more widespread and important role in other neurological states such as the occurrence of 'little strokes' previously thought to be largely associated with atheroma of the carotid arteries.

We would like to thank Mr. J. Hardman and Mr. A. A. Jefferson, of the Department of Neurosurgery, United Sheffield Hospitals, for their permission to use clinical information on their cases; Dr. A. J. Coup, of the Department of Pathology, Sheffield University, for permission to use case 1 on which he performed the postmortem examination, The Department of Medical Illustration, United Sheffield Hospitals, for their help with the photography, and Mr. K. Horton, Chief Technician in the Department of Neuropathology, for his technical help. 


\section{REFERENCES}

Clarkson, A. R., MacDonald, M. K., Fuster, V., Cash, J. D., and Robson, J. S. (1970). Glomerular coagulation in acute ischaemic renal failure. Quarterly Journal of Medicine, 39, 585-599.

Fearnley, G. R. (1965). Fibrinolysis. Arnold: London.

Goldenfarb, P. B., Zucker, S., Corrigan, J. J., Jr., and Cathey, M. H. (1970). The coagulation mechanism in acute bacterial infection. British Journal of Haematology, 18, 643-652.

Graham, D. I., and Adams, J. H. (1971). Ischaemic brain damage in fatal head injuries. Lancet, 1, 265-266.

Hardaway, R. M. (1966). Syndromes of Disseminated Intravascular Coagulation. Thomas: Springfield, Ill.

Larrieu, M. J., Rigollot, C., and Marder, V. J. (1972). Comparative effects of fibrinogen degradation fragments $D$ and E on coagulation. British Journal of Haematology, 22, 719733.

McKay, D. G. (1965). Disseminated Intravascular Coagulation. Harper and Row: New York.
Marder, V. J., and Shulman, N. R. (1969). High molecular $\underset{\mathbb{D}}{Z}$ weight derivatives of human fibrinogen produced by plasmin. 2. Mechanism of their anticoagulant activity. Journal of Biological Chemistry, 244, 2120-2124.

Nalbandian, R. M., Henry, R. L., Kessler, D. L., Camp, F. R., Jr., and Wolf, P. L. (1971). Consumption coagulo- $\square$ pathy: practical principles of diagnosis and management. Human Pathology, 2, 377-388.

Nolf, P. (1908). Contribution à l'étude de la coagulation du sang. 5. La fibrinolyse. Archives Internationales de Physiologie, 6, 306-359.

Preston, F. E., Malia, R. G., Sworn, M. J., and Blackburn, $\overrightarrow{\overrightarrow{7}}$ E. K. (1972a). Intravascular coagulation and renal failure $\stackrel{5}{\rightarrow}$ in $E$. coli septicaemia. (Abstract.) Journal of Clinical Pathology, 25, 1006-1007.

Preston, F. E., Malia, R. G., Sworn, M. J., and Blackburn, $\overline{\bar{c}}$ E. K. (1972b). Intravascular coagulation and $E$. coli septicaemia. Journal of Clinical Pathology, 26, 120-125.

Regoeczi, E., and Brain, M. C. (1969). Organ distribution of fibrin in disseminated intravascular coagulation. British Journal of Haematology, 17, 73-81. 